\title{
Evolution of DMSP (dimethylsulfoniopropionate) biosynthesis pathway: Origin and phylogenetic distribution in polyploid Spartina (Poaceae, Chloridoideae)
}

Hélène Rousseau ${ }^{1}$, Mathieu Rousseau-Gueutin ${ }^{2}$, Xavier Dauvergne ${ }^{3}$, Julien Boutte ${ }^{1}$, Gaëlle Simon ${ }^{4}$, Nathalie Marnet ${ }^{5}$, Alain Bouchereau ${ }^{2}$, Solène Guiheneuf ${ }^{6}$, Jean-Pierre Bazureau ${ }^{6}$, Jérôme Morice ${ }^{2}$, Stéphane Ravanel ${ }^{7}$, Francisco Cabello-Hurtado ${ }^{1}$, Abdelkader Ainouche ${ }^{1}$, Armel Salmon ${ }^{1}$, Jonathan F. Wendel ${ }^{8}$, Malika L. Ainouche ${ }^{1}$

1: UMR CNRS 6553 Ecobio. Université de Rennes 1, Campus de Beaulieu, 35042 Rennes Cedex, France; ${ }^{2}$ : UMR IGEPP, INRA, Agrocampus Ouest, Université de Rennes 1, BP35327, F-35653 Le Rheu Cedex, France ; ${ }^{3}$ : EA 2219 Géoarchitecture. Université de Bretagne Occidentale, 6 av. le Gorgeu - CS 9383729238 Brest Cedex 3, France; ${ }^{4}$ : Plateforme technologique de Résonance Magnétique Nucléaire, Résonance Paramagnétique Electronique et Spectrométrie de Masse. 6, av. Victor Le Gorgeu. CS93837, 29238 Brest Cedex 3, France; 5: Plateau de Profilage Métabolique et Métabolomique (P2M2), Centre de Recherche Angers Nantes BIA, INRA de Rennes, F-35653 Le Rheu, France; ${ }^{6}$ : UMR CNRS 6226, Groupe Ingénierie Chimique \& Molécules pour le Vivant (ICMV), Sciences Chimiques de Rennes. Université de Rennes 1, Campus de Beaulieu, 35042 Rennes Cedex, France; ${ }^{7}$ : Laboratoire de Physiologie Cellulaire \& Végétale, UMR 5168 CNRS-CEA-UMR 1417 INRA-Université Grenoble Alpes, Grenoble, France; ${ }^{8}$ : Department of Ecology, Evolution, and Organismal Biology, lowa State University, Ames, IA 50011, USA

Author for correspondence: Malika Ainouche Tel: +332232351 11 / Email: malika.ainouche@univ-rennes1.fr 


\section{Summary}

DMSP (dimethylsulfoniopropionate) is an ecologically important sulfur metabolite commonly produced by marine algae and by some higher plant lineages, including the polyploid salt marsh genus Spartina (Poaceae). The molecular mechanisms and genes involved in the DMSP biosynthesis pathways are still unknown. In this study, we performed comparative analyses of DMSP amounts and molecular phylogenetic analyses to decipher the origin of DMSP in Spartina that represents one of the major source of terrestrial DMSP in coastal marshes. DMSP content was explored in 14 Spartina species using ${ }^{1} \mathrm{H}$ Nuclear Magnetic Resonance (NMR) spectroscopy and Ultra Performance Liquid Chromatography-Mass Spectrometry (UPLC-MS). Putative genes encoding the four enzymatic steps of the DMSP biosynthesis pathway in Spartina were examined and their evolutionary dynamics were studied. We found that the hexaploid lineage containing S. alterniflora, S. foliosa and S. maritima and their derived hybrids and allopolyploids are all able to produce DMSP, in contrast to species in the tetraploid clade. Thus, examination of DMSP synthesis in a phylogenetic context implicated a single origin of this physiological innovation, which occurred in the ancestor of the hexaploid Spartina lineage, 3-6 MYA. Candidate genes specific to the Spartina DMSP biosynthesis pathway were also retrieved from Spartina transcriptomes, and provide a framework for future investigations to decipher the molecular mechanisms involved in this plant phenotypic novelty that has major ecological impacts in saltmarsh ecosystems.

Key words: Cordgrass, Gene phylogeny, Genome duplication, Phenotypic novelty 


\section{Introduction}

Elucidating the genomic determinants of physiological and phenotypic innovations is a major challenge of ecological and evolutionary genomics. Such innovations need to be explored in a historical context toward comparative and integrative approaches (Byers et al., 2016). The history of plant diversification is punctuated by recurrent whole genome duplication (polyploidy) events and subsequent diploidization and genome fractionation, which shaped modern plant genomes (Wendel et al., 2016). These processes undoubtedly have helped increase the physiological and adaptive potential of many lineages. Comparative approaches conducted in a well-understood phylogenetic context help inform the mechanisms involved in the evolution of new functions. Here, we aim to understand the evolution of an ecologically important function, namely DMSP synthesis in the polyploid genus Spartina Schreb.

DMSP (dimethylsulfoniopropionate) is one of the major sulfonium compounds in marine environments. It has long fascinated plant biologists and ecologists, thanks to its uneven distribution across specific eukaryotic lineages, and because of its ecological role in marine ecosystems (reviewed in Stefels, 2000). The DMSP released by producer organisms is a key molecule in marine food webs, where microorganisms use it as a main sulphur source (Yoch, 2002). DMSP catabolites, such as the volatile DMS (dimethylsulfide), also have an ecological impact, being involved in the global sulfur cycle, in acid precipitation and in climate regulation (Andreae and Raemdonck, 1983; Aneja, 1990; Barnard et al., 1982; Charlson et al., 1987; Malin et al., 1992; Nguyen et al., 1978; Nriagu et al., 1987). This gas is also implicated in cloud nuclei formation, increasing cloud reflectance and thus albedo (Charlson et al., 1987; Yoch, 2002). 
DMSP is commonly produced in marine algae, including green and red macro algae, or coccolithophores, diatoms and dinoflagellate. It is also found in some corals (Raina et al., 2013), but occurs only rarely in higher plants (reviewed in Dickschat et al., 2015). In monocots, significant amounts of DMSP have only been reported in Spartina and in a few Saccharum L. species, including sugarcane (S. officinarum L., Paquet et al., 1994). In Spartina, DMSP was first discovered in Spartina anglica C.E. Hubb. (Larher et al., 1977), but later in Spartina alterniflora Loisel (Colmer et al., 1996; Dacey et al., 1987; Husband et al., 2012; Kiehn and Morris, 2010; McFarlin and Alber, 2013; Otte and Morris, 1994), Spartina foliosa Trin. (Otte and Morris, 1994) and Spartina maritima (Curtis) Fernald (Otte and Morris, 1994). The capacity to produce DMSP was also tested in Spartina patens (Aiton) Muhl. and Spartina cynosuroides (L.) Roth, but no DMSP was detected in these species (Dacey et al., 1987). In eudicots, DMSP has only been found in Wollastonia biflora (L.) Wild., Asteraceae (Storey et al., 1993). DSMP has mostly been studied in leaves, where it is believed to be synthesized in chloroplasts (Trossat et al., 1996).

While the pathways and genes involved in the DMSP catabolism are well characterized (reviewed in Curson et al., 2011), little is known about the genetics and evolutionary origin of DMSP biosynthesis. As implied by the phylogenetic distribution and rarity of DMSP production in flowering plants, synthesis must have evolved independently at least three times (Stefels, 2000). In a series of studies, Hanson and co-workers (Hanson et al., 1994; James et al., 1995; Kocsis et al., 1998) showed that DMSP synthesis proceeds by a distinct route in angiosperms compared to marine algae and dinoflagellates, and involves different intermediate steps in the Asteraceae versus the Poaceae. In Wollastonia, DMSP synthesis is performed via three enzymatic steps (resulting in two intermediate metabolites: S-methylmethionine (SMM) and DMSP-amine), whereas the Spartina pathway involves four enzymatic steps with three intermediate compounds (SMM, DMSP-amine and DMSP-aldehyde). Whereas the first and last enzymatic steps are performed in Spartina species that do not produce 
DMSP (and are common to all angiosperms), the second and third steps are specific to DMSPproducing Spartina species (Kocsis et al., 1998). The first step, catalyzed by the MMT enzyme, corresponds to the conversion of methionine into SMM (Bourgis et al., 1999) and the fourth step, catalyzed by BADH enzyme, converts DMSP-aldehyde into DMSP (Trossat et al., 1997; Vojtěchová et al., 1997). The intermediate specific steps involve (i) the conversion of SMM to DMSP-amine by an Smethyl-Met decarboxylase (SDC) related to an ornithine decarboxylase, and (ii) the conversion of DMSP-amine to DMSP-aldehyde by an oxidase (DOX) related to a diamine oxidase (Kocsis et al., 1998; Kocsis and Hanson, 2000). The protein sequences of these enzymes, as well as their corresponding genes, are unknown.

Various DMSP functions have been proposed, but remain unproven. As most DMSP producing species live in marine environments or exhibit salt-tolerance, an osmoregulatory role was suggested early-on (Colmer et al., 1996; Dickson et al., 1980; Diggelen et al., 1986; Karsten et al., 1992; Kirst, 1996; Mulholland and Otte, 2002; Otte et al., 2004; Otte and Morris, 1994; Storey et al., 1993). DMSP may also have other functions, such as antioxidant (Husband et al., 2012; Husband and Kiene, 2007; McFarlin and Alber, 2013; Raina et al., 2013; Sunda et al., 2002) or cryoprotectant (Karsten et al., 1996) properties. Relationships between DMSP and the salicylic acid pathway (involved in pathogen resistance) were suggested in Spartina (Kiehn and Morris, 2010). Some authors also detected a negative effect of dieback on DMSP concentrations in leaves or stems (Kiehn and Morris, 2010; McFarlin and Alber, 2013). These studies indicate that DMSP function is not fully elucidated, and that it may vary among species.

Here we report the first exhaustive survey of DMSP production in the genus Spartina, analyzed in the light of phylogenetic history. Spartina (Poaceae, Chloridoideae) is a monophyletic, polyploid perennial grass genus embedded in the paraphyletic genus Sporobolus R.Br.(Peterson et al., 2010, 
2014); this led Peterson et al., (2014) to propose (i) inclusion of Spartina in a large, monophyletic genus Sporobolus, and (ii) conservation of the name Sporobolus over the older generic names Spartina, Calamovilfa, Crypsis, and Thellungia In this study, we kept the former Spartina names (that were used in the relevant literature of DMSP), and we provide a synonym list referring to the new nomenclature in Table 1 . Several Spartina species play an important ecological role in the coastal saltmarsh sedimentary dynamics, where they are considered "ecosystem engineers" (Ainouche et al., 2009). Spartina includes two main lineages, one tetraploid $(2 n=4 x=40)$, which mostly diversified in the New World (subsect. Ponceletia and subsect. Spartina, Peterson et al. 2014, table 1), and one hexaploid ( $2 n=6 x=60,62$ which are now included in subsect. Alterniflori (Peterson et al., 2014, table 1), containing two American and weakly divergent sister species, S. alterniflora and S. foliosa, and a third Euro-African species, S. maritima (Baumel, 2002, Peterson et al. 2014). No diploid Spartina species are known, which suggests that Spartina evolved from an already polyploid ancestor (as the most closely related species are also polyploid), about 12-20 MYA (Rousseau-Gueutin et al., 2015). Hybridization within and between these two lineages resulted in various ploidy levels $(7 x, 8 x, 9 x, 12 x$, Ainouche et al., 2012; Strong and Ayres, 2013). Of particular interest is the reticulate history involving hybridization between S. alterniflora (as maternal parent) and S. maritima (as paternal parent) in Western Europe during the $19^{\text {th }}$ century, which resulted in the independent formation of two sterile hybrids: Spartina $x$ neyrautii Foucaud (in southwest France) and Spartina $x$ townsendii H\&J Groves (in southern England). Genome duplication in S. $x$ townsendii resulted in a fertile new allododecaploid species (S. anglica), which rapidly expanded in range and has now invaded several continents (Ainouche et al., 2009). This system represents a classical model of recent allopolyploid speciation (Gray et al., 1991), and is used in various studies to explore the short-term consequences of hybridization and genome duplication in a well-understood historical frame (Ainouche et al., 2012, 2004; Ainouche and Wendel, 2014). 
Previous studies indicate that Spartina contains both DMSP-producing and non-producing species (reviewed in Otte et al., 2004), but there remains a need for a more exhaustive survey. Here, we addressed the following questions: (i) What are the DMSP producing (DMSP+) and non-producing (DMSP-) species in Spartina? (ii) Does DMSP production have single or multiple origin? (iii) Is the ability to produce DMSP related to polyploidy per se? (iv) What are the effects of hybridization and polyploidy on DMSP amounts in the DMSP+ species? (v) What are the Spartina genes putatively involved in the DMSP biosynthesis pathway? We hypothesized that polyploid speciation would have played a central role in the DMSP production ability and concentration, and that this function is phylogenetically constrained.

To answer these questions, DMSP amounts were determined in species representing all Spartina lineages, in different tissues and conditions, using ${ }^{1} \mathrm{H}$ NMR spectroscopy and UPLC-MS, and the DMSP production ability was examined in the light of Spartina phylogeny. Effects of increased salinity in species that usually do not produce DMSP are explored for the first time. Genes involved in the DMSP biosynthesis pathway are retrieved from Spartina transcriptomes and gene phylogenies and comparative analyses with model grass genomes are performed.

\section{Materials and Methods}

\subsection{Plant material and sampling}

Fourteen Spartina taxa were used in this study (Table 2), encompassing the various ploidy levels (tetraploid, hexaploid, heptaploid, octoploid, nonaploid and dodecaploid) known in this group and verified using flow cytometry analyses (Ainouche M. unpublished). Specimens are conserved either as herbarium or dried leaf samples or maintained in the greenhouse at University of Rennes 1 (table 2). The nonaploid plant introduced in this study was described in Renny-Byfield et al. (2010) and is 
believed to result from a backcross between $S$. anglica and its maternal parent $S$. alterniflora. Plant materials were collected in the field and maintained in a growth chamber under controlled freshwater conditions (14h light at $20^{\circ} \mathrm{C} / 10 \mathrm{~h}$ dark at $18^{\circ} \mathrm{C}$ with $80 \%$ of hygrometry). Plant tissues (leaves, roots or inflorescences, see below) were harvested and immediately frozen in liquid nitrogen and stored at $-80^{\circ} \mathrm{C}$. They were then lyophilized and ground.

\subsection{DMSP quantification}

For ${ }^{1} \mathrm{H}$ NMR spectroscopy analyses, $100 \mathrm{mg}$ of each sample were extracted with $1.5 \mathrm{ml}$ of $50 \%$ methanol, vortexed quickly, agitated gently for 20 minutes and centrifuged at $4000 \mathrm{~g}$ for 5 minutes. These extraction steps were performed two more times after dissolving the obtained pellet in $1 \mathrm{ml}$ of $50 \%$ methanol. The supernatants were collected after each extraction, gathered and dried with a rotary evaporator. For UPLC-MS, the same protocol was applied except that $50 \mathrm{mg}$ of sample was used and the added volumes were adjusted accordingly. For this method, $1 \%$ formic acid was incorporated to the $50 \%$ methanol solution and the supernatant was not dried. Heptafluorobutyric acid (HFBA) at $50 \mathrm{mM}$ was added to the supernatants.

DMSP production was first explored among the different Spartina species using ${ }^{1} \mathrm{H}$ NMR spectroscopy. It was tested in leaves, and when possible in roots or inflorescences. Extracts were dissolved in $800 \mu$ l of $D_{2} \mathrm{O}$. A BRUKER Avance 400 spectrometer equipped with a $5 \mathrm{~mm}$ inverse TBI $1 \mathrm{H} /\{\mathrm{BB}\} / 31 \mathrm{P}$ probe was used. The spectra were performed with a $30^{\circ}$ pulse using a $10 \mathrm{~s}$ delay at $25^{\circ} \mathrm{C}$. Calculation of DMSP concentrations was based on integration of NMR peaks, and areas of peaks corresponding to this metabolite were compared to the trimethylsilyl propionate (TSP) peak of known concentration.

A UPLC-MS method, which is more sensitive than ${ }^{1} \mathrm{H}$ NMR (Pan and Raftery, 2007), was also performed on the extracts of all Spartina species grown in the growth chamber (Table 2). For each 
species, at least two biological and technical replicates were performed. Because DMSP is commercially unavailable and to generate a standard, DMSP was synthesized using the protocol described by Zhang et al., (2007) for the synthesis of 3-(Sulfonium-1-yl)propanoic acid. Dimethylsulphide (Sigma Aldrich) $(1.03 \mathrm{ml}, 13.94 \mathrm{mmol})$ and acrylic acid $(957 \mu \mathrm{l}, 13.94 \mathrm{mmol})$ were dissolved in $7.4 \mathrm{ml}$ of acetone at $0^{\circ} \mathrm{C} . \mathrm{HCl} 10 \mathrm{M}(2.9 \mathrm{ml})$ was added and the mixture was stirred at room temperature for $27 \mathrm{~h}$. The excess $\mathrm{HCl}$ was removed by evaporation under reduced pressure and the residue was washed twice with $7 \mathrm{ml}$ ethyl acetate. After decanting, DMSP was identified in the aqueous layer that was evaporated under vacuum at $40^{\circ} \mathrm{C}$. The grey solid obtained was crystallized from diethyl ether/methanol (1:1; V/V) (Zhou et al., 2009). Filtration led to a white powder identified as DMSP (999 mg, 42\% yield). Its purity was determined using ${ }^{1} \mathrm{H}$ NMR spectrometer (Avance $300 \mathrm{MHz}$; Bruker) and was found to be higher than 95\%.

For UPLC separation, extracts were filtered through PTFE membranes $(0,45 \mu \mathrm{m} ; 25 \mathrm{~mm})$ before injection. The UPLC Acquity system (Waters) used for separation and quantification of DMSP contained a binary gradient pump where solvent $A$ was $1 \mathrm{mM}$ HFBA $+0,1 \%$ propionic acid and solvent B was acetonitrile $+0,1 \%$ propionic acid. This system was equipped with a C18 BEH 1,7 $\mu \mathrm{m}$ 2,1×100 mm (Waters) column. The separation started by an isocratic step from 0 to $1 \mathrm{~min}$ at $10 \% \mathrm{~B}$, from 1 to 9 min linear gradient until $90 \%$ B, from 9 to 9.5 min isocratic $90 \%$, from 9.5 to $11 \mathrm{~min}$ linear gradient until $10 \% \mathrm{~B}$, the last step was from 11 to $12 \mathrm{~min}$ isocratic $10 \% \mathrm{~B}$. The flow rate was 0.7 $\mathrm{ml} \mathrm{min}{ }^{-1}$ during all the run time. $1 \mu \mathrm{l}$ of sample solution was injected. The column temperature was kept at $45^{\circ} \mathrm{C}$. Detection of compounds was performed using a TripleQuadrupole detector (Waters) with the ESI (ElectroSpray Ionisation) positive mode by MultiReactionMonitoring (MRM). MS parameters to detect DMSP compound were as follows: capillary voltage $4500 \mathrm{~V}$, source temperature $150^{\circ} \mathrm{C}$, desolvation temperature $450^{\circ} \mathrm{C}$, desolvation gas flow rate $800 \mathrm{~L} \mathrm{hour}^{-1}$. The extraction cone voltage was $26 \mathrm{~V}$; the collision energy voltage was $17 \mathrm{~V}$. Data were collected using the QuanLynx software (Waters). 


\subsection{Salt treatment}

Three Spartina species, namely Spartina pectinata Link cv. Aureomarginata), Spartina versicolor Fabre (Kouali, Algeria) and Spartina anglica (La Richardais, France) were subjected to a salt treatment. Modified Hoagland solutions (Table S1) with three different sodium chloride concentrations were prepared $\left(0 \mathrm{~g} \mathrm{~L}^{-1}, 10 \mathrm{~g} \mathrm{~L}^{-1}\right.$ and $\left.35 \mathrm{~g} \mathrm{~L}^{-1}\right)$. For S. pectinata and S. versicolor, two biological replicates per condition were performed whereas triplicates were used for $S$. anglica. The plants were first washed to remove sediments, placed into plastic jars filled with sand and acclimated for four weeks in a climatic chamber. The pots were then submerged in the prepared $\mathrm{NaCl}$ solution for $15 \mathrm{~min}$ to saturate the substrate, as described in Otte and Morris (1994). This treatment was renewed every two days. Leaves were harvested after two weeks of treatment. The plant DMSP content was then analyzed using the UPLC-MS method.

\subsection{Statistical analyses}

Statistical analyses were conducted using the R software (R Development Core Team. 2012). To detect potential significant differences between species, a one-way ANOVA was performed on log transformed DMSP concentrations values. Data obtained from the salinity experiments were also analyzed using a one-way ANOVA. The $\alpha$ level for significance was $P \leq 0.05$ for all tests.

\subsection{Evolutionary dynamics of genes involved in the DMSP pathway}

The DMSP biosynthesis pathway in Spartina involves four enzymes (Fig. 1): (i) Methionine Smethyltransferase or MMT, (ii) SDC, (iii) DOX, and (iv) DMSP-aldehyde dehydrogenase corresponding to the betaine aldehyde dehydrogenase (BADH) (Trossat et al., 1997; Vojtěchová et al., 1997). This latter enzyme is a member of the ALDH (aldehyde dehydrogenase) superfamily. Genes encoding these enzymes were searched in Viridiplantae databases and compared to Spartina sequences. 
To explore the evolutionary dynamics of the $m m t$ and aldh genes, all $m m t$ (one copy) and aldh (14 copies) sequences in Arabidopsis were retrieved from TAIR (www.arabidopsis.org). BLASTP (e-value threshold of $10^{-50}$; (Altschul et al., 1997)) of $A$. thaliana copies for these genes were performed against 41 fully sequenced plant genomes available on Phytozome (www.phytozome.net) for $\mathrm{mmt}$ and on fewer species for aldh, considering the high copy number of this gene family: Physcomitrella patens, and various Angiosperm lineage representatives (Chase et al. 2016): all Poaceae species available in Phytozome (Sorghum bicolor, Zea mays, Setaria italica, Panicum virgatum, Oryza sativa and Brachypodium distachyon), one Asterid (Mimulus guttatus) and five Rosids, including two Eurosid I (Medicago truncatula, Populus trichocarpa), two Eurosid II (Arabidopsis thaliana, Gossypium raimondii) and Vitis vinifera. These genes were also searched in Spartina by performing a tBLASTn (evalue threshold of $10^{-6}$; Altschul et al., 1997) of the Arabidopsis $\mathrm{mmt}$ and aldh gene sequences against the leaf and root transcriptomes of four hexaploid (S. maritima, S. alterniflora, S. $x$ townsendii and S. $x$ neyrautii) and one allododecaploid Spartina species (S. anglica) (Boutte et al., 2016; Ferreira et al., 2013). Amino-acid sequences of either the $\mathrm{mmt}$ or the aldh genes were aligned using Geneious (version 6.1.8; Biomatters). The accession numbers or Spartina contigs of the $m m t$ and aldh sequences considered in the phylogenetical analyses are provided in Table S2 and S4, respectively. Moreover, the Spartina mmt and aldh amino acid sequences are given in Table S3 and S5, respectively. The BADH4 sequence (Beta vulgaris), which was shown to be involved in the conversion of DMSP-aldehyde into DMSP (Trossat et al., 1997), was also included in the aldh analysis. After manually adjusting the alignments, the best model of evolution was identified using Modeltest implemented in MEGA 5.2.1 (Tamura et al., 2011) for both data matrices: JTT + G and WAG + G for $m m t$ and aldh genes respectively. Maximum Likelihood (ML) phylogenetic analyses (1000 bootstrap replicates) were performed using MEGA with Physcomotrella patens as outgroup. The nonsynonymous/synonymous rate ratio (dN/dS) was also studied for both genes using Yang (2007). 
These ratios were calculated using either nucleotide sequences corresponding to the entire CDS, the functional domains, or the genic region used in phylogenetic analyses.

To explore whether the different ALDH copies have retained their function, we examined the amino acids corresponding to the catalytic site (presence of a cysteine in active enzymes: Farres et al., 1995; Kopečný et al., 2011) and those involved in substrate specificity in all sequences used in the phylogeny. We also examined the amino acids implicated in ALDH10 substrate specificity, allowing the specific binding of $\omega$-aminoaldehydes, which correspond to an aspartic acid (D) and a serine (S) at the position 110 and 292 of the Spinacia oleracea sequence, respectively (Riveros-Rosas et al., 2013). We also looked at the amino-acid at position 441 in Spinacia oleracea that is believed to be determinant for substrate specificity of BADH: high substrate affinity for betaine aldehyde in presence of an alanine (A) or a cysteine (C), or low affinity in the presence of an isoleucine (I) (DiazSanchez et al., 2012).

Putative sdc and dox genes were first searched in O. sativa, Z. mays and S. bicolor from Phytozome using keyword search and BLASTP (e-value threshold of $10^{-6}$; Altschul et al., 1997). Only genes presenting a decarboxylase or amine oxidase domain using Pfam (e-value threshold of $10^{-3}$; (Finn et al., 2014) were retained. A tBLASTn (e-value threshold of $10^{-6}$; Altschul et al., 1997) of these remaining sequences was then performed against the five DMSP+Spartina transcriptomes (Boutte et al., 2016). A few other putative Spartina $s d c$ and dox sequences were additionally identified using functional annotations of Spartina contigs (Boutte et al., 2016). To determine if the same $s d c$ and dox genes are present in the different Spartina transcriptomes, the homologous relationship between $O$. sativa and Spartina sdc and dox sequences was identified by BLASTn ( $\geq 70 \%$ of identity, $\geq 60 \mathrm{pb}$ of overlap) and represented graphically using Circos (Krzywinski et al., 2009).

\section{Results}




\subsection{DMSP content analysis}

The ability of the different Spartina species to produce DMSP (DMSP+) was first screened using ${ }^{1} \mathrm{H}$ NMR analyses. S. maritima, S. alterniflora, S. foliosa and their hybrid (S. $x$ neyrautii and S. $x$ townsendii) or allopolyploid derivatives (S. anglica and the 9x hybrid) were all found to produce DMSP (Fig. 2) in all tested tissues (leaves, roots and inflorescences). In all other Spartina species (Spartina argentinensis Parodi, S. pectinata, S. gracilis Trin., S. bakeri, S. versicolor, S. arundinacea (Thouars) Carmich.) no DMSP was detected, including the $S$. pectinata individuals presenting different ploidy levels (tetraploid, hexaploid or octoploid); these species are hereafter termed "DMSP-". The heptaploid species Spartina densiflora Brongn., which derives from the hexaploid S. alterniflora (DMSP+) and the tetraploid S. arundinacea (DMSP-), has inherited the ability to produce this compound.

The concentration of DMSP was quantified in several organs of S. alterniflora and S. anglica (using ${ }^{1} \mathrm{H}$ NMR), and was found to be higher in leaves than in roots or inflorescences. DMSP concentration in S. alterniflora was $19.53 \mu \mathrm{mol}$ g-1 MS in leaves, compared to 2.27 and $3.31 \mu \mathrm{mol}$ g- $1 \mathrm{MS}$ in roots and inflorescences, respectively. Similarly, S. anglica exhibits $11.92 \mu \mathrm{mol}$ g-1 MS of DMSP in leaves compared to 3.89 and $6.90 \mu \mathrm{mol}$ g-1 MS in roots and inflorescences.

DMSP amounts were further analyzed in Spartina leaves using the more sensitive UPLC-MS method. A DMSP standard solution was first characterized to ensure accurate identification in the UPLC-MS analyses. This compound eluted at 0.53 minutes. DMSP ion was observed on MS spectra at $135 \mathrm{~m} / \mathrm{z}$ and its fragment at $73 \mathrm{~m} / \mathrm{z}$ corresponding to one of its fragmentation ion, i.e. acrylic acid (Spielmeyer and Pohnert, 2010). The limit of quantification (LOQ) was $0.23 \mu \mathrm{g} \mathrm{ml}^{-1}$ for DMSP. Using this sensitive method, we observed that the Spartina species previously detected as DMSP- using ${ }^{1} \mathrm{H}$ NMR were confirmed as DMSP- (Table 2 and Table S6, Supporting Information). 
DMSP concentrations in Spartina DMSP+ (Table S6, Supporting Information) were compared by performing a one-way ANOVA on log transformed data $(\mathrm{F}=4.729 ; \mathrm{p}=0.008)$. This analysis indicates that S. alterniflora contains significantly more DMSP in the leaves than do S. anglica $(p=0.004)$ and $S$. $x$ townsendii ( $p=0.030$ ) (Fig. 3). In addition, we noted the following differences, but without statistical significance: (i) the tested S. alterniflora individuals tend to produce more DMSP than S. maritima; (ii) S. $x$ neyrautii genotypes display intermediate DMSP production compared to its parents $S$. alterniflora and S. maritima; (iii) S. x townsendii contains a DMSP concentration closer to its paternal parent S. maritima; (iv) S. $x$ neyrautii tends to produce more DMSP than the other F1 hybrid, S. $x$ townsendii; $(\mathrm{v})$ the allododecaploid S. anglica presents a similar concentration to S. $x$ townsendii despite its genome doubling; and (vi) S. foliosa tends to produce less DMSP than its closely related species, S. alterniflora..

DMSP concentration was also determined in S. pectinata and S. versicolor (DMSP-) and in S. anglica (DMSP+, as positive control) grown for two weeks in the presence of various $\mathrm{NaCl}$ concentrations. Salt treatment had no significant effect on DMSP concentrations in S. anglica (ANOVA; F=0.452; $\mathrm{p}=0.656$ ). DMSP was not detected in any S. versicolor and S. pectinata individuals, irrespective of $\mathrm{NaCl}$ concentration.

\subsection{Evolutionary dynamics of genes involved in DMSP biosynthesis}

\subsubsection{Gene encoding MMT}

The $m m t$ sequences were retrieved from fully sequenced Viridiplantae genomes (phytozome) as well as from Spartina transcriptomes (partial transcripts), corresponding to 44 sequences obtained from 36 species (Table S2, Supporting Information). The resulting data matrix of 411 amino acids, corresponding to exons 6 to 11 of the 0 . sativa $m m t$ gene (Fig. 4), was subjected to Maximum Parsimony (MP) and Maximum Likelihood (ML) phylogenetic analyses. The tree topology (similar in 
both analyses) is in agreement with the expected angiosperm phylogeny, with the monocot (represented by Poales) and the eudicot species present in two separate clades (Fig. 5). The $m m t$ gene is present in single copy in most Embryophytes, but two $m m t$ gene sequences were found in eight species (Fig. 5). In all cases, the two copies present in one species are grouped together. $m m t$ contigs were detected in three of the five considered Spartina transcriptomes: one in S. alterniflora, one in S. maritima, and three in S. $x$ townsendii. For phylogenetic analyses, only the Spartina $x$ townsendii $\mathrm{mmt}$ contig that is longer than 400 amino-acids was considered. Pairwise synonymous and non-synonymous substitution rates for the $m m t$ gene indicate purifying selection when considering either the region used for phylogeny (mean $\mathrm{dN} / \mathrm{dS}$ ratios $=0.088$ ) (Table 3), the whole CDS (mean $\mathrm{dN} / \mathrm{dS}$ ratios $=0.096$ ) or each functional domain (mean $\mathrm{dN} / \mathrm{dS}$ ratios of 0.177 and 0.043 for methyltransferase and aminotransferase domain respectively).

\subsubsection{Genes encoding ALDH}

The badh gene ( $4^{\text {th }}$ step of Spartina DMSP biosynthesis pathway) belongs to the aldehyde dehydrogenase (aldh) family. Within this family, 14 (in Arabidopsis thaliana) to 26 copies (in Panicum virgatum) were identified per species. In total, 272 sequences were retrieved (Table S4, Supporting Information) and aligned, yielding a data matrix of 403 amino acids for ML analysis. Sequences were grouped into 11 different major clades (denoted as "copy I" to "copy XI") corresponding to aldh paralogous genes (Fig. 6). All species have a copy in each clade, except a few that have lost one or two copies (e.g. no $O$. sativa copy in clade IV). Within clades, additional aldh gene duplications were observed in some lineages. For example, additional gene duplications occurred in Monocots within clades II, III, IX, X and XI (Fig. 6). Within Spartina, aldh transcript sequences were observed in 10 of the 11 major clades (except clades III and X). The BADH4 sequence, which is involved in the conversion of DMSP-aldehyde into DMSP, belongs to clade IX (named ALDH10 in (Kirch et al., 2004) and includes Spartina species (Fig. 6). 
The structure of all aldh genes was compared using $O$. sativa as a reference. Coding sequences range in size from 1272 to $1794 \mathrm{bp}$, and the number of exons varies from 8 to 20 (Fig. 4). Within a clade, a high conservation of exon synteny is observed even when a different number of exons is observed, presumably from intron loss (Fig. 4). Similarly, the size of intronic sequences may vary among aldh sequences (1101 to 7156 bp), even within clades (i.e. clade X). This variation is not explained by the presence of repeated elements (Fig. 4). dN/dS ratios were estimated for aldh sequences (genic region used in the phylogeny) and indicate purifying selection for each gene copy (dN/dS ranging from 0.001 to 0.758 , Table 3 ) or for all 0 . sativa paralogous copies ( $\mathrm{dN} / \mathrm{dS}=0.23$; Table 3 ). Similar results were observed when considering the entire CDS or the functional domain. To explore whether the different ALDH copies have retained their function, we examined the presence of a catalytic site as well as other amino acids implicated in the substrate specificity of some ALDH enzymes. Among the 293 ALDH sequences studied here, 289 sequences presented an active catalytic site (presence of a cysteine at that position). The four sequences lacking a cysteine at this site were found in species having another copy in which the cysteine was present (i.e. P. virgatum in clade IX). We also examined the amino acids implicated in ALDH10 substrate specificity (aspartic acid and a serine at the position 110 and 292 of the Spinacia oleracea sequence). We observed that all but two sequences retain these amino acids, the exceptions being species presenting another functional copy. In the ten other clades, we found different amino acids at those positions, suggesting different substrate specificity between ALDH10 and the other ALDH enzymes. Within clade IX (BADH gene), we looked at another amino-acid involved in substrate affinity (high affinity in presence of an alanine or a cysteine at position 441 in Spinacia oleracea, or low affinity in presence of an isoleucine). We observed the presence of at least one copy per species with a cysteine, alanine or isoleucine. DMSP+ Spartina species have both types of amino-acid implicated in the differential affinity for betaine aldehyde, and thus their BADH enzyme is likely to bind other $\omega$-aminoaldehydes, as DMSP-aldehyde. 


\subsubsection{Identification of putative sdc and dox genes}

The two steps of the Spartina DMSP biosynthesis pathway that are specific to DMSP+ species involve a S-methyl-Met decarboxylase (SDC) and a DMSP-amine oxidase (DOX) (Kocsis and Hanson, 2000). Genes encoding proteins with a decarboxylase or amine oxidase activity were retrieved in some Poaceae species: a total of 96,77 and 117 putative decarboxylase sequences were obtained for $O$. sativa, S. bicolor and Z. mays, respectively. Similarly, 34, 35 and 65 putative dox sequences were found. These putative $s d c$ and $d o x$ sequences (hereafter named $s d c$ and $d o x$ for simplicity) were identified in Spartina using tBLASTn against the five DMSP+ Spartina transcriptomes (Boutte et al., 2016; Ferreira et al., 2013). A total of 193 sdc contigs for S. alterniflora, 200 for S. maritima, 170 for S. $x$ townsendii, 152 for S. $x$ neyrautii and 163 for S. anglica were found (Table S7, Supporting Information). Concerning the putative dox contigs, 52 sequences were obtained for S. alterniflora, 65 for S. maritima, 54 for S. $x$ townsendii, 55 for S. x neyrautii and 53 for S. anglica (Table S8, Supporting Information). This contig number is higher than the number of corresponding genes as several contigs in a species may belong to a single gene. Within species, the presence of several Spartina contigs belonging to the same 0 . sativa homolog may be visualized in Fig. 7 .

Of the $96 s d c$. sativa genes, 30 to 41 orthologous genes were identified in Spartina species. Similarly, of the 34 dox O. sativa genes, 15 to 21 dox orthologous Spartina genes were found (Fig. 7). When considering all Spartina transcriptomes, a higher number of different $s d c(52)$ and dox (22) genes were obtained (Fig. S1, Supporting Information). Consideration of the Spartina transcriptomes enabled us to identify homologous contigs among Spartina species and to obtain homologous sequences in Spartina from almost all O. sativa exons (Fig. 7).

\section{Discussion}




\subsection{Monophyletic origin of DMSP production in Spartina}

Our results show that the ability to produce DMSP appeared once in Spartina, in the allohexaploid ancestor of S. maritima, S. alterniflora and S. foliosa (hereafter called the "hexaploid clade"), about 2 to 10 million years ago (Rousseau-Gueutin et al., 2015). All taxa derived from these hexaploids have inherited this ability, including the hexaploid hybrids and the allododecaploid S. anglica. Interestingly, the alloheptaploid S. densiflora, derived from a DMSP+ and a DMSP- species (Fortune et al., 2008) also inherited this ability. Although the metabolic pathway leading to the DMSP synthesis has been elucidated in some plants (Kocsis et al., 1998), little is known about mechanisms involved in DMSP production. Our results indicate that a genetically determined (i.e. heritable) mechanism (yet to be elucidated) is involved in DMSP synthesis. The presence of DMSP is not related to ploidy level increase per se, as our analyses reveal that DMSP is not produced in autohexaploid and octoploid cytotypes derived from the tetraploid S. pectinata (Kim et al., 2010). The tetraploid S. argentinensis that represents a distinct lineage in the genus, being placed either as sister of all other Spartina species or as sister of the hexaploid clade (Baumel et al. 2002, Fortune et al. 2007, 2008, Peterson et al. 2014) does not produce DMSP. The auto or allopolyploid nature of the hexaploid DMSP+ ancestor is not fully established. Discerning allopolyploidy from autopolyploidy is not an easy task in relatively old polyploids (especially when diploids are extinct), but the presence of divergent homoeologous gene copies in the hexaploid DMSP+ S. maritima and S. alterniflora (Boutte et al., 2015; Fortune et al., 2007) suggest a reticulate origin of this clade. This history raises the question as to whether gene duplication, combined with merger of divergent genomes, led to the emergence of this new function. It is difficult to know whether this function arose immediately following the formation of the hexaploid DMSP+ ancestor, or occurred following subsequent evolution of this ancestral lineage. Several examples of phenotypic and physiological novelties entailed by the short term and/or the long-term evolution of hybrid and polyploid genomes have been identified, such as 
the free threshing character ( $\mathrm{Q} / \mathrm{q}$ locus) and grain hardness (Ha locus) in polyploid wheat (Chantret, 2005; Zhang et al., 2011). In grasses, DMSP amounts have also been detected in some Saccharum species, including the domesticated polyploid sugarcane S. officinarum and its wild ancestor $S$. robustum (Paquet et al., 1994). Much lower quantities were reported in S. spontaneum, although amounts may vary among different varieties. DMSP+ Spartina and Saccharum species, which occupy coastal marsh and cultivated areas respectively, appear to be the main terrestrial source of atmospheric sulfur produced via DMSP degradation (Dacey et al., 1987). It would be of interest to perform comparative analyses to determine whether the ability to synthesize DMSP, which evolved independently in polyploid Spartina and Saccharum, involved similar genetic and/or regulatory mechanisms. Sugarcane and related species have a complex genetic history, involving various ploidy levels, aneuploidy and hybridization (Grivet et al., 2006, 2004), and an exhaustive screening of DMSP amounts in the various cytotypes is lacking.

\subsection{Reticulation, polyploidy, and variation in DMSP amounts}

DMSP is unevenly distributed among organs of the DMSP+ Spartina species. We found that DMSP content is higher in leaves than in roots or inflorescences. This result agrees with previous studies (Dacey et al., 1987; Mulholland and Otte, 2002, 2000; Otte and Morris, 1994). Trossat et al. (1996) have explored the subcellular localization of the different DMSP biosynthesis steps in Wollastonia biflora, and found that the first step (conversion of methionine into SMM by the MMT enzyme) is cytosolic, whereas the other steps leading to DMSP are performed in the chloroplasts, which may explain the higher DMSP content in leaves than in roots or inflorescences.

As mentioned in the introduction, an osmoprotectant or osmoregulatory role for DMSP has been hypothesized, and this role is still under debate for DMSP producing plants (Otte et al., 2004). Within Spartina, it appears that all DMSP+ species naturally grow in low marsh zones and tolerate several 
hours of immersion in sea water at high tides, whereas DMSP- species preferentially occupy high marsh or inland zones (Mobberley, 1956). Salinity was previously found to have no effect on S. alterniflora and S. anglica (Colmer et al., 1996; Diggelen et al., 1986; Otte and Morris, 1994), and we obtained similar results in this study for S. anglica. Our analyses of DMSP- species (S. versicolor and S. pectinata) also reveal that the presence of $\mathrm{NaCl}$ does not induce DMSP production.

We also explored the effect of recent hybridization and polyploidy on DMSP. When comparing the F1 hybrids S. $x$ townsendii and S. $x$ neyrautii to their parents (i.e. S. alterniflora and S. maritima), we found that S. $x$ neyrautii exhibits an intermediate level of DMSP production compared to its parents (parental additivity), whereas the other F1 hybrid S. $x$ townsendii has a DMSP production similar to $S$. maritima (paternal dominance). Thus, independent hybridization events involving the same maternal and paternal species (Baumel et al., 2003) appear to have different effects on DMSP amounts. These different effects of hybridization are also conspicuous at the morphological and gene expression levels in S. $x$ townsendii and S. $x$ neyrautii (Baumel et al., 2003; Foucaud, 1897; Hubbard et al., 1978): comparative global transcriptomic studies found both additive and non-additive parental gene expression in these hybrids, with maternal (similar to S. alterniflora) expression dominance most frequently encountered (and more pronounced in S. $x$ townsendii), and a series of differentially expressed genes between these two hybrids (Chelaifa et al., 2010; Chelaifa et al., unpublished).

The effects of recent genome duplication on DMSP amounts were explored by comparing the hexaploid S. $x$ townsendii to its dodecaploid derivative S. anglica: no effect on DMSP amounts was observed, which suggests dosage compensation on the genetic system involved in this case. Moreover, we found that the hexaploid S. alterniflora produces significantly more DMSP than the hexaploid S. $x$ townsendii and the dodecaploid S. anglica. S. alterniflora also produces more DMSP than its closely related sister hexaploid species S. foliosa. The nonaploid Spartina hybrid (deriving 
from S. alternifora and S. anglica) and the heptaploid S. densiflora seem to produce less DMSP than S. alterniflora. Thus, DMSP concentration seems not to be affected by increasing ploidy level per se.

\subsection{Evolutionary dynamics of genes involved in the DMSP pathway}

We explored genes encoding the enzymes involved in the first (MMT) and last (BADH) steps of DMSP synthesis. We found that the MMT enzyme is present in single copy in most Embryophytes, but that in a few species two mmt sequences were observed, likely arising from relatively recent polyploidization events. For example, $P$. virgatum, which exhibits two $m m t$ copies, underwent a whole genome duplication 0.5 to 1 MYA (Garsmeur et al., 2014). This gene most likely plays an important function: indeed, the product of the $m m t$ enzyme (namely the SMM compound) is implicated in sulfur transport in plants and may be involved in the grain protein synthesis (Bourgis et al., 1999). It is then not surprising that this low copy number gene is under high selective constraint.

In contrast to $m m t$, the badh gene belongs to a complex aldh multigene family with 14 to 26 copies in the angiosperm species considered here. The proteins encoded by these different copies seem to be active, with intact open reading frames, conserved putative catalytic sites, and with evidence of purifying selection. Similar examples of duplicated genes retention through numerous polyploidization events have already been observed for genes involved in protein complexes, including genes encoding ribosomes, proteasomes (Freeling, 2006) or genes involved in the photosystem II protein complex (Coate et al., 2011). Within the aldh gene family, the retention of the different copies may be related to different substrate specificities or tissue specificities. Different aldh genes are involved in multiple functions related to the oxidation of amino aldehydes. Kirch et al. (2004) noted that different ALDH genes are involved in diverse roles, such as male sterility, plant defense and abiotic stress tolerance. Moreover, some aminoaldehyde dehydrogenases were shown 
to oxidize various substrates but with different catalytic efficiencies (Kopecny et al., 2013; RiverosRosas et al., 2013).

The ALDH10 clade, containing the BADH enzyme, is the only ALDH family present in the 20 studied species that is thought to convert $\omega$-aminoaldehydes. This is bioinformatically confirmed here by the analysis of the two amino acids conferring $\omega$-aminoaldehyde specificity (D110, S292), which are only present in sequences of this clade. Different copies of ALDH10 may have been maintained partly because BADH is able to bind different substrates, such as betaine aldehyde, DMSP aldehyde or other $\omega$-aminoaldehydes, with different efficiencies (Kopecny et al., 2013; Trossat et al., 1997). It has been shown that a single amino acid is responsible for the substrate specificity of the BADH enzyme (Diaz-Sanchez et al., 2012). Interestingly, Sorghum bicolor, known to accumulate glycine betaine in response to stress, exhibits a cysteine whereas an isoleucine is present in Arabidopsis thaliana and Oryza sativa, which do not accumulate glycine betaine (Rhodes and Hanson, 1993). In Spartina, our results suggest that DMSP+ species may bind different $\omega$-aminoaldehydes substrates, including DMSP-aldehyde.

In addition to the analysis of known genes involved in the non-specific steps of DMSP production, we performed exploratory analyses of sequences annotated as decarboxylase or amine oxidase to target genes encoding the SDC and DOX enzymes, which were found specific to DMSP production in Spartina (Kocsis and Hanson, 2000). Candidate genes were identified in the transcriptomes of five DMSP+ species, opening new perspectives on the possibility of performing comparative transcriptomic analyses between DMSP- and DMSP+ species.

In summary, the present study provides a clear view of the phylogenetic context and the genetic transmission of DMSP production in polyploid Spartina species, and provides a framework for future 
investigations to decipher the molecular mechanisms involved in this plant phenotypic novelty that has major ecological impacts in saltmarsh ecosystems.

\section{Acknowledgements}

We thank the Chemical Sciences Institute of Rennes (UMR CNRS 6226) for DMSP synthesis, as well as the Metabolic and Metabolomic Profiling (P2M2, INRA Le Rheu, France) and the NMR-EPR-MS Technology (Brest, France) platforms for DMSP detection and quantification. J. Keller is thanked for his help during the salt treatment experiment, F. Nassur and T. Fontaine for the maintenance of the Spartina plant collection in the greenhouse. We thank D.K. Lee, S. Kim, D. Strong, S. Rinehart, E. Chow, R. Klinger and T. Columbus, who kindly helped us obtain American Spartina samples.

\section{Fundings}

We thank the "Région Bretagne", the Partner University Fund and the European Union Seventh Framework Program [FP7-CIG-2013 - 2017; grant no. 333709 to M.R.-G.], the CNRS and University of Rennes 1 (LIA ECOGEN) for financial support. 


\section{References}

Ainouche, M., Chelaifa, H., Ferreira de Carvalho, J., Ainouche, A., Salmon, A., 2012. From-Polyploid Evolution in Spartina: Dealing with Highly Redundant Hybrid Genomes, in: Polyploidy and Genome Evolution. Soltis PS, Soltis DE (Eds.), Springer Verlag, Berlin Heidelberg, pp. 225-243.

Ainouche, M.L., Baumel, A., Salmon, A., 2004. Spartina anglica CE Hubbard: a natural model system for analysing early evolutionary changes that affect allopolyploid genomes. Biol. J. Linn. Soc. $82,475-484$.

Ainouche, M.L., Fortune, P.M., Salmon, A., Parisod, C., Grandbastien, M.-A., Fukunaga, K., Ricou, M., Misset, M.-T., 2009. Hybridization, polyploidy and invasion: lessons from Spartina (Poaceae). Biol. Invasions 11, 1159-1173.

Ainouche, M., Wendel, J., 2014. Polyploid Speciation and Genome Evolution: Lessons from Recent Allopolyploids, in: Evolutionary Biology: Genome Evolution, Speciation, Coevolution and Origin of Life. Pontarotti P (Eds), Springer Verlag, Berlin Heidelberg, pp. 87-113.

Andreae, M.O., Raemdonck, H., 1983. Dimethyl sulfide in the surface ocean and the marine atmosphere: a global view. Science 221, 744-747.

Aneja, V.P., 1990. Natural Sulfur Emissions into the Atmosphere. J. Air Waste Manag. Assoc. 40, 469476.

Barnard, W.R., Andreae, M.O., Watkins, W.E., Bingemer, H., Georgii, H.-W., 1982. The flux of dimethylsulfide from the oceans to the atmosphere. J. Geophys. Res. Oceans 87, 8787-8793.

Baumel, A., 2002. Molecular Phylogeny of Hybridizing Species from the Genus Spartina Schreb. (Poaceae). Mol. Phylogenet. Evol. 22, 303-314.

Baumel, A., Ainouche, M.L., Misset, M.T., Gourret, J.-P., Bayer, R.J., 2003. Genetic evidence for hybridization between the native Spartina maritima and the introduced Spartina alterniflora (Poaceae) in South-West France: Spartina $\times$ neyrautii re-examined. Plant Syst. Evol. 237, 8797.

Bourgis, F., Roje, S., Nuccio, M.L., Fisher, D.B., Tarczynski, M.C., Li, C., Herschbach, C., Rennenberg, H., Pimenta, M.J., Shen, T.-L., others, 1999. S-methylmethionine plays a major role in phloem sulfur transport and is synthesized by a novel type of methyltransferase. Plant Cell Online 11, 1485-1497.

Boutte, J., Aliaga, B., Lima, O., Ferreira de Carvalho, J., Ainouche, A., Macas, J., Rousseau-Gueutin, M., Coriton, O., Ainouche, M., Salmon, A., 2015. Haplotype Detection from Next-Generation Sequencing in High-Ploidy-Level Species: 45S rDNA Gene Copies in the Hexaploid Spartina maritima. Genes|Genomes|Genetics 6, 29-40.

Boutte, J., Ferreira de, C.J., Rousseau-Gueutin, M., Poulain, J., Da Silva, C., Wincker, P., Ainouche, M., Salmon, A., 2016. Reference transcriptomes and detection of duplicated copies in hexaploid and allododecaploid Spartina species (Poaceae). Genome Biol. Evol. 8, 3030-3044.

Byers, K., Xu, S., Schlüter, P., 2016. Molecular mechanisms of adaptation and speciation: why do we need an integrative approach? Mol. Ecol. 26, 277-290.

Chantret, N., 2005. Molecular Basis of Evolutionary Events That Shaped the Hardness Locus in Diploid and Polyploid Wheat Species (Triticum and Aegilops). PLANT CELL ONLINE 17, 1033-1045.

Charlson, R., Lovelock, J., Andreae, M., Warren, S., 1987. Oceanic phytoplancton, atmospheric sulphur, cloud albedo and climate. Nature 326, 655-661.

Chase, M.W., Christenhusz, M.J.M., Fay, M.F., Byng, J.W., Judd, W.S., Soltis, D.E., Mabberley, D.J., Sennikov, A.N., Soltis, P.S., Stevens, P.F., 2016. An update of the Angiosperm Phylogeny Group classification for the orders and families of flowering plants: APG IV. Bot. J. Linn. Soc. 181, 1-20. 
Chelaifa, H., Monnier, A., Ainouche, M., 2010. Transcriptomic changes following recent natural hybridization and allopolyploidy in the salt marsh species Spartina $\times$ townsendii and Spartina anglica (Poaceae). New Phytol. 186, 161-174.

Coate, J.E., Schlueter, J.A., Whaley, A.M., Doyle, J.J., 2011. Comparative Evolution of Photosynthetic Genes in Response to Polyploid and Nonpolyploid Duplication. PLANT Physiol. 155, 20812095.

Colmer, T.D., WM, F.T., Läuchli, A., Higashi, R.M., 1996. Interactive effects of salinity, nitrogen and sulphur on the organic solutes in Spartina alterniflora leaf blades. J. Exp. Bot. 47, 369-375.

Curson, A.R.J., Todd, J.D., Sullivan, M.J., Johnston, A.W.B., 2011. Catabolism of dimethylsulphoniopropionate: microorganisms, enzymes and genes. Nat. Rev. Microbiol. 9, 849-859.

Dacey, J.W.H., King, G.M., Wakeham, S.G., 1987. Factors controlling emission of dimethylsulphide from salt marshes. Nature 330, 643-645.

Diaz-Sanchez, A.G., Gonzalez-Segura, L., Mujica-Jimenez, C., Rudino-Pinera, E., Montiel, C., MartinezCastilla, L.P., Munoz-Clares, R.A., 2012. Amino Acid Residues Critical for the Specificity for Betaine Aldehyde of the Plant ALDH10 Isoenzyme Involved in the Synthesis of Glycine Betaine. PLANT Physiol. 158, 1570-1582.

Dickschat, J.S., Rabe, P., Citron, C.A., 2015. The chemical biology of dimethylsulfoniopropionate. Org Biomol Chem 13, 1954-1968.

Dickson, D.M., Jones, R.W., Davenport, J., 1980. Steady state osmotic adaptation in Ulva lactuca. Planta 150, 158-165.

Diggelen, J. van, Rozema, J., Dickson, D.M.J., Broekman, R., 1986. $\beta$-3-dimethylsulphoniopropionate, proline and quaternary ammonium compounds in Spartina anglica in relation to sodium chloride, nitrogen and sulphur. New Phytol. 103, 573-586.

Farres, J., Wang, T.T., Cunningham, S.J., Weiner, H., 1995. Investigation of the active site cysteine residue of rat liver mitochondrial aldehyde dehydrogenase by site-directed mutagenesis. Biochemistry (Mosc.) 34, 2592-2598.

Ferreira, J., Poulain, J., Da Silva, C., Wincker, P., Michon-Coudouel, S., Dheilly, A., Naquin, D., Boutte, J., Salmon, A., Ainouche, M., 2013. Transcriptome de novo assembly from next-generation sequencing and comparative analyses in the hexaploid salt marsh species Spartina maritima and Spartina alterniflora (Poaceae). Heredity 110, 181-193.

Finn, R.D., Bateman, A., Clements, J., Coggill, P., Eberhardt, R.Y., Eddy, S.R., Heger, A., Hetherington, K., Holm, L., Mistry, J., Sonnhammer, E.L.L., Tate, J., Punta, M., 2014. Pfam: the protein families database. Nucleic Acids Res. 42, D222-D230.

Fortune, P.M., Schierenbeck, K.A., Ainouche, A.K., Jacquemin, J., Wendel, J.F., Ainouche, M.L., 2007. Evolutionary dynamics of Waxy and the origin of hexaploid Spartina species (Poaceae). Mol. Phylogenet. Evol. 43, 1040-1055.

Fortune, P.M., Schierenbeck, K., Ayres, D., Bortolus, A., Catrice, O., Brown, S., Ainouche, M.L., 2008. The enigmatic invasive Spartina densiflora : A history of hybridizations in a polyploidy context. Mol. Ecol. 17, 4304-4316.

Foucaud, 1897. Un Spartina inédit. Ann. Société Sci. Nat. Charente Inférieure 32, 220-222.

Freeling, M., 2006. Gene-balanced duplications, like tetraploidy, provide predictable drive to increase morphological complexity. Genome Res. 16, 805-814.

Garsmeur, O., Schnable, J.C., Almeida, A., Jourda, C., D'Hont, A., Freeling, M., 2014. Two Evolutionarily Distinct Classes of Paleopolyploidy. Mol. Biol. Evol. 31, 448-454.

Gray, A.J., Marshall, D.F., Raybould, A.F., 1991. A century of evolution in Spartina anglica. Advances in Ecological Research 21, 1-62. 
Grivet, L., Daniels, C., Glaszmann, J.-C., D'Hont, A., 2004. A review of recent molecular genetics evidence for sugarcane evolution and domestication.

Grivet, L., Glaszmann, J.-C., D’Hont, A., 2006. Molecular evidences of sugarcane evolution and domestication, in: Darwin's Harvest. New Approaches to the Origins, Evolution, and Conservation of Crops. Motley T, Zerega N, Cross H (Eds.), Columbia University Press, New York,USA, pp. 49-66.

Hanson, A.D., Rivoal, J., Paquet, L., Gage, D.A., 1994. Biosynthesis of 3-Dimethylsulfoniopropionate in Wollastonia biflora (L.) DC. Plant Physiol. 105, 103-110.

Hubbard, J., Grimes, B., Marchant, C., 1978. Some observations on the ecology and taxonomy of Spartina $x$ neyrautii and Spartina alterniflora growing in France and Spain and comparison with Spartina $x$ townsendii and Spartina anglica. Doc. Phytosociol. 2, 273-282.

Husband, J.D., Kiene, R.P., 2007. Occurrence of dimethylsulfoxide in leaves, stems, and roots of Spartina alterniflora. Wetlands 27, 224-229.

Husband, J.D., Kiene, R.P., Sherman, T.D., 2012. Oxidation of dimethylsulfoniopropionate (DMSP) in response to oxidative stress in Spartina alterniflora and protection of a non-DMSP producing grass by exogenous DMSP+acrylate. Environ. Exp. Bot. 79, 44-48.

James, F., Paquet, L., Sparace, S.A., Gage, D.A., Hanson, A.D., 1995. Evidence implicating dimethylsulfoniopropionaldehyde as an intermediate in dimethylsulfoniopropionate biosynthesis. Plant Physiol. 108, 1439-1448.

Karsten, U., Kirst, G.O., Wiencke, C., 1992. Dimethylsulphoniopropionate (DMSP) accumulation in green macioalgae from polar to temperate regions: interactive effects of light versus salinity and light versus temperature. Polar Biol. 12, 603-607.

Karsten, U., Kück, K., Vogt, C., Kirst, G., 1996. Dimethylsulfoniopropionate production in phototrophic organisms and its physiological function as a cryoprotectant, in: Biological and Environmental Chemistry of DMSP and Related Sulfonium Compounds. Kiene RP, Visscher PT, Keller MD, Kirst GO (Eds.), Plenum Press, New York, USA, pp. 143-153.

Kiehn, W., Morris, J., 2010. Variability in dimethylsulfoniopropionate (DMSP) concentrations in Spartina alterniflora and the effect on Littoraria irrorata. Mar. Ecol. Prog. Ser. 406, 47-55.

Kim, S., Rayburn, A.L., Lee, D.K., 2010. Genome Size and Chromosome Analyses in Prairie Cordgrass. Crop Sci. 50, 2277.

Kirch, H.-H., Bartels, D., Wei, Y., Schnable, P.S., Wood, A.J., 2004. The ALDH gene superfamily of Arabidopsis. Trends Plant Sci. 9, 371-377.

Kirst, G., 1996. Osmotic adjustment in phytoplankton and macroalgae. The use of Dimethylsulfoniopropionate (DMSP), in: Biological and Environmental Chemistry of DMSP and Related Sulfonium Compounds. Kiene RP, Visscher PT, Keller MD, Kirst GO (Eds.), Plenum Press, New York, USA, pp. 121-129.

Kocsis, M.G., Hanson, A.D., 2000. Biochemical evidence for two novel enzymes in the biosynthesis of 3-dimethylsulfoniopropionate in Spartina alterniflora. Plant Physiol. 123, 1153-1162.

Kocsis, M.G., Nolte, K.D., Rhodes, D., Shen, T.-L., Gage, D.A., Hanson, A.D., 1998. Dimethylsulfoniopropionate Biosynthesis in Spartina alterniflora. Plant Physiol. 117, 273281.

Kopecny, D., Koncitikova, R., Tylichova, M., Vigouroux, A., Moskalikova, H., Soural, M., Sebela, M., Morera, S., 2013. Plant ALDH10 Family: IDENTIFYING CRITICAL RESIDUES FOR SUBSTRATE SPECIFICITY AND TRAPPING A THIOHEMIACETAL INTERMEDIATE. J. Biol. Chem. 288, 94919507.

Kopečný, D., Tylichová, M., Snegaroff, J., Popelková, H., Šebela, M., 2011. Carboxylate and aromatic active-site residues are determinants of high-affinity binding of $\omega$-aminoaldehydes to plant aminoaldehyde dehydrogenases: Site-directed mutagenesis of plant aminoaldehyde dehydrogenase. FEBS J. 278, 3130-3139. 
Krzywinski, M., Schein, J., Birol, I., Connors, J., Gascoyne, R., Horsman, D., Jones, S.J., Marra, M.A., 2009. Circos: An information aesthetic for comparative genomics. Genome Res. 19, 16391645.

Larher, F., Hamelin, J., Stewart, G.R., 1977. L’acide diméthylsulfonium-3 propanoïque de Spartina anglica. Phytochemistry 16, 2019-2020.

Malin, G., Turner, S., Liss, P., 1992. Sulfur: the plankton/climate connection. J. Phycol. 28, 590-597.

McFarlin, C., Alber, M., 2013. Foliar DMSO:DMSP ratio and metal content as indicators of stress in Spartina alterniflora. Mar. Ecol. Prog. Ser. 474, 1-13.

Mobberley, D., 1956. Taxonomy and Distribution of the Genus Spartina. Iowa State Coll J Sci 30, 471574.

Mulholland, M.M., Otte, M.L., 2002. The effects of nitrogen supply and salinity on DMSP, glycine betaine and proline concentrations in leaves of Spartina anglica. Aquat. Bot. 72, 193-200.

Mulholland, M.M., Otte, M.L., 2000. Effects of varying sulphate and nitrogen supply on DMSP and glycine betaine levels in Spartina anglica. J. Sea Res. 43, 199-207.

Nguyen, B., Gaudry, A., Bonsang, B., Lambert, G., 1978. Reevaluation of the role of dimethyl sulphide in the sulfur budge. Nature 275, 637-639.

Nriagu, J., Holdway, D., Coker, R., 1987. Biogenic Sulfur and the Acidity of Rainfall in Remote Areas of Canada. Science 237, 1189-1192.

Otte, M.L., Morris, J.T., 1994. Dimethylsulphoniopropionate (DMSP) in Spartina alterniflora Loisel. Aquat. Bot. 48, 239-259.

Otte, M.L., Wilson, G., Morris, J.T., Moran, B.M., 2004. Dimethylsulphoniopropionate (DMSP) and related compounds in higher plants. J. Exp. Bot. 55, 1919-1925.

Pan, Z., Raftery, D., 2007. Comparing and combining NMR spectroscopy and mass spectrometry in metabolomics. Anal. Bioanal. Chem. 387, 525-527.

Paquet, L., Rathinasabapathi, B., Saini, H., Zamir, L., Gage, D.A., Huang, Z.H., Hanson, A.D., 1994. Accumulation of the compatible solute 3-dimethylsulfoniopropionate in sugarcane and its relatives, but not other gramineous crops. Funct. Plant Biol. 21, 37-48.

Peterson, P.M., Romaschenko, K., Arrieta, Y.H., Saarela, J.M., 2014. A molecular phylogeny and new subgeneric classification of Sporobolus (Poaceae: Chloridoideae: Sporobolinae). Taxon 63, 1212-1243. Peterson, P.M., Romaschenko, K., Johnson, G., 2010. A classification of the Chloridoideae (Poaceae) based on multi-gene phylogenetic trees. Mol. Phylogenet. Evol. 55, 580-598.

Raina, J.-B., Tapiolas, D.M., Forêt, S., Lutz, A., Abrego, D., Ceh, J., Seneca, F.O., Clode, P.L., Bourne, D.G., Willis, B.L., Motti, C.A., 2013. DMSP biosynthesis by an animal and its role in coral thermal stress response. Nature 502, 677-680. Rhodes, D., Hanson, A.D., 1993. Quaternary ammonium and tertiary sulfonium compounds in higher plants. Annu. Rev. Plant Biol. 44, 357-384.Renny-Byfield, S., Ainouche, M., Leitch, I.J., Lim, K.Y., Le Comber, S.C., Leitch, A.R., 2010. Flow cytometry and GISH reveal mixed ploidy populations and Spartina nonaploids with genomes of S. alterniflora and S. maritima origin. Ann. Bot. 105, 527-533. doi:10.1093/aob/mcq008

Riveros-Rosas, H., González-Segura, L., Julián-Sánchez, A., Díaz-Sánchez, Á.G., Muñoz-Clares, R.A., 2013. Structural determinants of substrate specificity in aldehyde dehydrogenases. Chem. Biol. Interact. 202, 51-61.

Rousseau-Gueutin, M., Bellot, S., Martin, G.E., Boutte, J., Chelaifa, H., Lima, O., Michon-Coudouel, S., Naquin, D., Salmon, A., Ainouche, K., others, 2015. The chloroplast genome of the hexaploid Spartina maritima (Poaceae, Chloridoideae): Comparative analyses and molecular dating. Mol. Phylogenet. Evol. 93, 5-16. 
Spielmeyer, A., Pohnert, G., 2010. Direct quantification of dimethylsulfoniopropionate (DMSP) with hydrophilic interaction liquid chromatography/mass spectrometry. J. Chromatogr. B 878, 3238-3242.

Stefels, J., 2000. Physiological aspects of the production and conversion of DMSP in marine algae and higher plants. J. Sea Res. 43, 183-197.

Storey, R., Gorham, J., Pitman, M.G., Hanson, A.D., Gage, D., 1993. Response of Melanthera biflora to salinity and water stress. J. Exp. Bot. 44, 1551-1560.

Strong, D.R., Ayres, D.R., 2013. Ecological and Evolutionary Misadventures of Spartina. Annu. Rev. Ecol. Evol. Syst. 44, 389-410.

Sunda, W., Kieber, D.J., Kiene, R.P., Huntsman, S., 2002. An antioxidant function for DMSP and DMS in marine algae. Nature 418, 317-320.

Tamura, K., Peterson, D., Peterson, N., Stecher, G., Nei, M., Kumar, S., 2011. MEGA5: Molecular Evolutionary Genetics Analysis Using Maximum Likelihood, Evolutionary Distance, and Maximum Parsimony Methods. Mol. Biol. Evol. 28, 2731-2739.

Trossat, C., Nolte, K.D., Hanson, A.D., 1996. Evidence that the pathway of dimethylsulfoniopropionate biosynthesis begins in the cytosol and ends in the chloroplast. Plant Physiol. 111, 965-973.

Trossat, C., Rathinasabapathi, B., Hanson, A.D., 1997. Transgenically expressed betaine aldehyde dehydrogenase efficiently catalyzes oxidation of dimethylsulfoniopropionaldehyde and $\omega$ aminoaldehydes. Plant Physiol. 113, 1457-1461.

Vojtěchová, M., Hanson, A.D., Muñoz-Clares, R.A., 1997. Betaine-aldehyde dehydrogenase from amaranth leaves efficiently catalyzes the NAD-dependent oxidation of dimethylsulfoniopropionaldehyde to dimethylsulfoniopropionate. Arch. Biochem. Biophys. $337,81-88$.

Wendel, J.F., Jackson, S.A., Meyers, B.C., Wing, R.A., 2016. Evolution of plant genome architecture. Genome Biol. 17.

Yoch, D.C., 2002. Dimethylsulfoniopropionate: Its Sources, Role in the Marine Food Web, and Biological Degradation to Dimethylsulfide. Appl. Environ. Microbiol. 68, 5804-5815.

Zhang, Y., Hudock, M.P., Krysiak, K., Cao, R., Bergan, K., Yin, F., Leon, A., Oldfield, E., 2007. Activity of Sulfonium Bisphosphonates on Tumor Cell Lines. J. Med. Chem. 50, 6067-6079.

Zhang, Z., Belcram, H., Gornicki, P., Charles, M., Just, J., Huneau, C., Magdelenat, G., Couloux, A., Samain, S., Gill, B.S., others, 2011. Duplication and partitioning in evolution and function of homoeologous Q loci governing domestication characters in polyploid wheat. Proc. Natl. Acad. Sci. 108, 18737-18742.

Zhou, C.-X., Xu, J.-L., Yan, X.-J., Hou, Y.-D., Jiang, Y., 2009. Analysis of Dimethylsulfide and Dimethylsulfoniopropionate in Marine Microalgae Culture. Chin. J. Anal. Chem. 37, 13081312. 
Table 1. Spartina revised nomenclature

New nomenclature: Sporobolus sect. Spartina (Schreb.) P.M. Peterson \& Saarela, com. \& stat. nov. Former nomenclature

Sporobolus subsect. Alterniflori P.M. Peterson \& Saarela, subsect. nov.

Sporobolus alterniflorus (Loisel.) P.M.Peterson \& Saarela, comb. nov.

Spartina alterniflora Loisel.

Sporobolus anglicus (C.E.Hubb.) P.M.Peterson \& Saarela, comb. nov.

Spartina anglica C.E.Hubb.

Sporobolus foliosus (Trin.) P.M.Peterson \& Saarela, comb. nov.

Sporobolus maritimus (Curtis) P.M.Peterson \& Saarela, comb. nov.

Sporobolus xtownsendii (H.Groves \& J.Groves) P.M.Peterson \& Saarela, comb. nov.

Spartina foliosa Trin

Spartina maritima (Curtis) Fernald

Spartina $\times$ townsendii H.Groves \& J.Groves

Sporobolus subsect. Ponceletia (Thouars) P.M. Peterson \& Saarela, comb. \& stat. nov.

Sporobolus mobberleyanus P.M.Peterson \& Saarela, nom. nov.

Sporobolus spartinus (Trin.) P.M.Peterson \& Saarela, comb. nov.

Spartina arundinacea (Thouars) Carmich.

Spartina spartinae (Trin.) Merr., syn. Spartina argentinensis

Sporobolus subsect. Spartina (Schreb.) P.M. Peterson \& Saarela, comb. \& stat. nov.

Sporobolus bakeri (Merr.) P.M.Peterson \& Saarela, comb. nov.

Sporobolus densiflorus (Brongn.) P.M.Peterson \& Saarela, comb. nov.

Spartina bakeri Merr.

Sporobolus hookerianus P.M.Peterson \& Saarela, nom. nov.

Spartina densiflora Brongn.

Spartina gracilis Trin.

Sporobolus michauxianus (Hitchc.) P.M.Peterson \& Saarela, comb. nov.

Spartina pectinata Link

Sporobolus versicolor (Fabre) P.M.Peterson \& Saarela, comb. nov.

Spartina versicolor Fabre 
Table 2. Origin and growth conditions of the Spartina samples analyzed using either ${ }^{1} \mathrm{H}$ NMR spectroscopy or UPLC-MS: the ploidy level of the different samples as well as the organs harvested and the number of replicates performed per species (between brackets) are also indicated.

\begin{tabular}{|c|c|c|c|c|c|}
\hline Species & $\begin{array}{c}\text { Ploidy } \\
\text { level } \\
(x=10)\end{array}$ & Origin & Sample conditions & ${ }^{1} \mathrm{H}$ NMR analysis & $\begin{array}{l}\text { UPLC-MS } \\
\text { analysis }\end{array}$ \\
\hline S. alterniflora Loisel & $6 \mathrm{x}$ & Finistère, France (Le Faou); Hampshire, England (Hythe) & growth chamber & $\begin{array}{l}\text { leaves (3), roots (2), } \\
\text { inflorescences (2) }\end{array}$ & leaves (3) \\
\hline S. anglica C.E. Hubb. & $12 \mathrm{x}$ & $\begin{array}{l}\text { Ille-et-Vilaine, France (La Guimorais); Morbihan, France (Le } \\
\text { Hezo); Côtes-d'Armor, France (Mordreuc Pleudihen-sur- }\end{array}$ & growth chamber & $\begin{array}{l}\text { leaves (8), roots (1), } \\
\text { inflorescences (2) }\end{array}$ & leaves (3) \\
\hline S. argentinensis Parodi & $4 \mathrm{x}$ & $\begin{array}{l}\text { Arman } \\
\text { Argentina, Santa Fe }\end{array}$ & $\begin{array}{l}\text { herbarium (Univ. } \\
\text { Rennes 1) }\end{array}$ & leaves (1) & \\
\hline S. arundinacea (Thouars) & $4 \mathrm{x}$ & Amsterdam Island, France & $\begin{array}{l}\text { herbarium (Univ. } \\
\text { Rennes 1) }\end{array}$ & leaves (1) & \\
\hline S. bakeri Merr. & $4 \mathrm{x}$ & Florida, USA & growth chamber & leaves (3), roots (1) & leaves (3) \\
\hline S. densiflora Brongn. & $7 \mathrm{x}$ & Andalusia, Spain (Odiel) & growth chamber & leaves (2) & leaves (2) \\
\hline S. foliosa Trin. & $6 \mathrm{x}$ & California, USA (Dog Beach, Chula Vista) & growth chamber & leaves (5) & leaves (2) \\
\hline S. gracilis Trin. & $4 \mathrm{x}$ & California, USA (Bischop) & growth chamber & & leaves (3) \\
\hline S. maritima (Curtis) Fern. & $6 \mathrm{x}$ & Morbihan, France (Le Hezo, Quenouille) & growth chamber & leaves (3) & leaves (3) \\
\hline S. $x$ neyrautii Foucaud & $6 \mathrm{x}$ & Pyrénées-Atlantiques, France (Hendaye) & growth chamber & leaves (5) & leaves (3) \\
\hline S. pectinata Link & $4 \mathrm{x}$ & commercialized Aureomarginata cultivar & growth chamber & leaves (2) & leaves (2) \\
\hline S. pectinata Link & $6 \mathrm{x}$ & Illinois, USA & greenhouse & leaves (1) & \\
\hline S. pectinata Link & $8 \mathrm{x}$ & South Dakota, USA & greenhouse & leaves (1) & \\
\hline S. $\mathrm{x}$ townsendii H\&J Groves & $6 \mathrm{x}$ & Hampshire, England (Hythe, Hayling Island) & growth chamber & leaves (5) & leaves (3) \\
\hline S. versicolor Fabre & $4 \mathrm{x}$ & $\begin{array}{l}\text { Hérault, France (Frontignan-Aresquiers); Var, France (Vieux } \\
\text { Salins); Algeria (Kouali) }\end{array}$ & growth chamber & leaves (3), roots (2) & leaves (2) \\
\hline Hybrid 9x & $9 \mathrm{x}$ & Hampshire, England (Marchwood) & growth chamber & leaves (2) & leaves (2) \\
\hline
\end{tabular}


Table 3. Comparison of non-synonymous $(\mathrm{dN})$ and synonymous $(\mathrm{dS})$ ratios obtained for $m m t$ and aldh sequences. This ratio was studied for different sequence alignments, i.e. using the coding region used for phylogenies, using all CDS or the functional domains of $m m t$ and aldh sequences. For aldh, these comparisons were performed within each major clade for the coding region used for phylogeny, whereas only the clade IX was analyzed on all CDS and functional domain. $\mathrm{dN} / \mathrm{dS}$ ratio was calculated for the three types of regions for $m m t$ and 0 . sativa aldh paralogs.

\begin{tabular}{|c|c|c|}
\hline Sequences analyzed & $\begin{array}{c}\text { Mean dN/dS (Min- } \\
\text { Max) }\end{array}$ & $\begin{array}{c}\begin{array}{c}\text { Coding region } \\
\text { analyzed }\end{array} \\
\end{array}$ \\
\hline$m m t$ & $0.088(0.016-0.718)$ & Same as phylogeny \\
\hline mmt & $0.096(0.030-2.245)$ & All CDS \\
\hline mmt methyltransferase domain & $0.177(0.004-0.723)$ & Functional domain \\
\hline$m m t$ aminotransferase domain & $0.043(0.009-0.228)$ & Functional domain \\
\hline aldh clade I & $0.095(0.031-0.758)$ & Same as phylogeny \\
\hline aldh clade II & $0.095(0.030-0.276)$ & Same as phylogeny \\
\hline aldh clade III & $0.082(0.002-0.500)$ & Same as phylogeny \\
\hline aldh clade IV & $0.075(0.028-0.657)$ & Same as phylogeny \\
\hline aldh clade $\mathrm{V}$ & $0.034(0.012-0.098)$ & Same as phylogeny \\
\hline aldh clade VI & $0.072(0.022-0.253)$ & Same as phylogeny \\
\hline aldh clade VII & $0.099(0.023-0.377)$ & Same as phylogeny \\
\hline aldh clade VIII & $0.087(0.023-0.279)$ & Same as phylogeny \\
\hline aldh clade IX & $0.082(0.020-0.465)$ & Same as phylogeny \\
\hline aldh clade IX & $0.092(0.024-0.217)$ & All CDS \\
\hline aldehyde dehydrogenase domain (clade IX only) & $0.122(0.012-1.095)$ & Functional domain \\
\hline aldh clade $\mathrm{X}$ & $0.045(0.001-0.172)$ & Same as phylogeny \\
\hline aldh clade XI & $0.065(0.007-0.657)$ & Same as phylogeny \\
\hline All aldh copies (O. sativa only) & $0.230(0.007-0.693)$ & Same as phylogeny \\
\hline All aldh copies (O. sativa only) & $0.295(0.008-1.016)$ & All CDS \\
\hline aldehyde dehydrogenase domain (O. sativa only) & $0.414(0.008-1.363)$ & Functional domain \\
\hline
\end{tabular}




\section{Figure Legends}

Fig. 1 DMSP biosynthesis pathway in Spartina, as proposed by Kocsis and Hanson (2000). Enzymes are indicated in italic. The first and the last steps are widely distributed among angiosperms whereas the intermediate steps (2 and 3 ) are specific to DMSP-producing species.

Fig. 2 Detection of DMSP in Spartina species. Phylogenetic relationships are redrawn from Ainouche et al. (2012). Spartina species that are able and unable to produce DMSP (using either ${ }^{1} \mathrm{H}$ NMR or UPLC-MS) are indicated in red and blue, respectively. The ploidy level of each tested species is indicated with brackets. Molecular dating of the tetraploid and hexaploid clades is obtained from Rousseau-Gueutin et al. (2015).

Fig. 3 Mean DMSP concentrations (in $\mu \mathrm{mol} \mathrm{g}^{-1} \mathrm{MS}$ ) in Spartina leaves: dots with different associated letters correspond to values statistically different at the $5 \%$ level. Standard errors are indicated.

Fig. 4 Structure of $m m t$ and aldh genes in Oryza sativa. Exons are represented by boxes. Colored boxes correspond to functional domains: blue to methyltransferase, orange to aminotransferase and pink to aldehyde dehydrogenase. Hatched boxes represent coding regions used for phylogenetic analyses. Within clades, corresponding exon regions from different aldh sequences are indicated with numbers. Transposable elements (DNA transposons and retrotransposons) and simple repeats are represented with diamonds.

Fig. $5 \mathrm{ML}$ analysis of the $m m t$ gene in Viridiplantae (JTT+G model; bootstrap 1000). Physcomitrella patens was used as outgroup. Bootstrap values (\%) are noted above branches; the number of substitutions per site is indicated below branches. The Spartina $\mathrm{mmt}$ sequence is indicated in bold. Polyploidy events (as reported by Garsmeur et al., 2014) are represented by stars.

Fig. $6 \mathrm{ML}$ analysis (50\% consensus tree) of the aldh gene family in Viridiplantae (WAG+G model; bootstrap 1000). Physcomitrella patens (sequences indicated by black diamonds) was used as outgroup. Bootstrap values (\%) are shown for nodes of the different BADH copies. ALDH copies (roman letters) and Monocots/Eudicots clades are indicated. Within a clade (aldh gene copy), duplications specific to Monocots are represented by capital letters. aldh Spartina sequences, retrieved from Spartina transcriptomic data, are represented by red dots. The position of the Beta vulgaris $\mathrm{BADH} 4$ sequence that was shown to perform the conversion of DMSP-aldehyde into DMSP (Trossat et al. 1997) is indicated (copy IX clade).

Fig. 7 Physical localization of the O. sativa sdc (96) and dox (34) genes and identification of their homologs in Spartina transcriptomic data. The first outer circle represents the twelve $O$. sativa chromosomes. Oryza sativa chromosomes are drawn to scale and their sizes are indicated between brackets. $s d c$ and dox genes are represented by red and blue triangles, respectively: triangles facing the inside or outside of the circles denote sense or antisense strands in the $O$. sativa genome. The exon number of each $O$. sativa gene is indicated above each triangle outside the outer circle. On the five other inner circles are represented the Spartina contigs homologous to the $s d c$ and dox $O$. sativa genes: the $O$. sativa exons present in each Spartina contig are noted above each triangle. 


\section{Supporting Information}

Additional supporting information may be found in the online version of this article.

Table S1. Hoagland solution used in the experiments

Table S2. Accession or Spartina contig numbers for the different Angiosperm $\mathrm{mmt}$ sequences used in this study.

Table S3. Sequences of the Spartina mmt contigs used in the phylogenetical analysis.

Table S4. Accession or Spartina contig numbers for the different Angiosperm aldh sequences used in this study.

Table S5. Sequences of the Spartina aldh contigs used in the phylogenetical analysis.

Table S6. DMSP concentrations obtained for each Spartina individual using UPLC-MS. The values presented for each individual result from mean values of two technical replicates.

Table S7. Putative sdc contigs identified in Spartina transcriptomes.

Table S8. Putative dox contigs identified in Spartina transcriptomes.

Fig. S1 Physical localization of the $O$. sativa sdc (96) and dox (34) genes in the $O$. sativa genome and identification of their homologs in Spartina transcriptomic data.

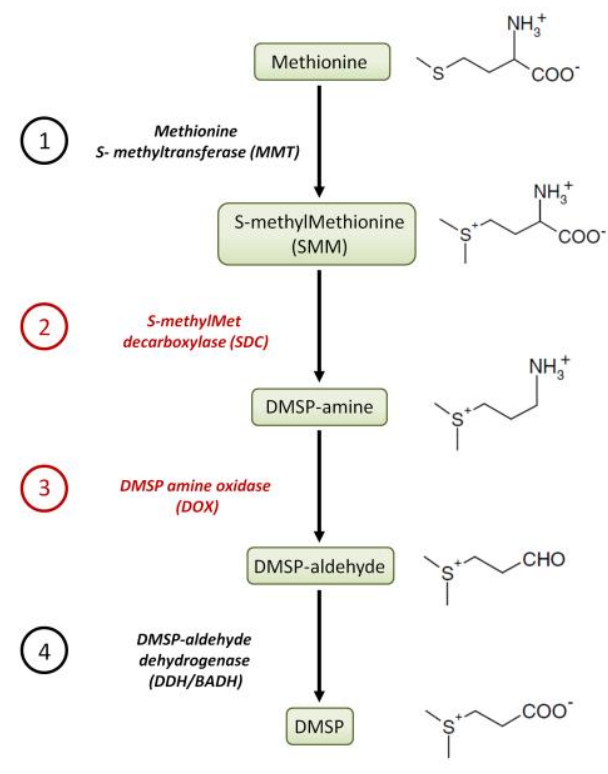



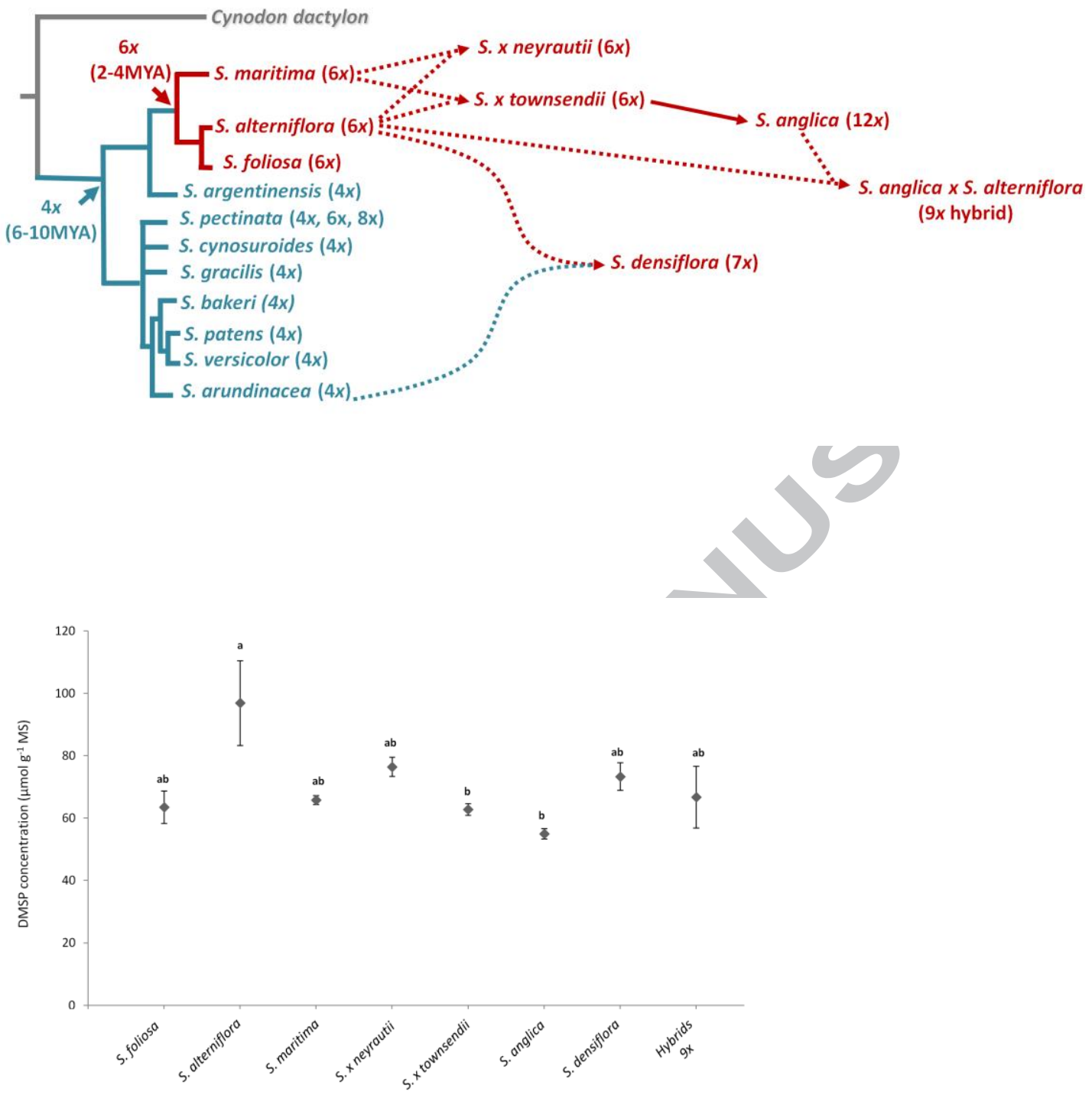


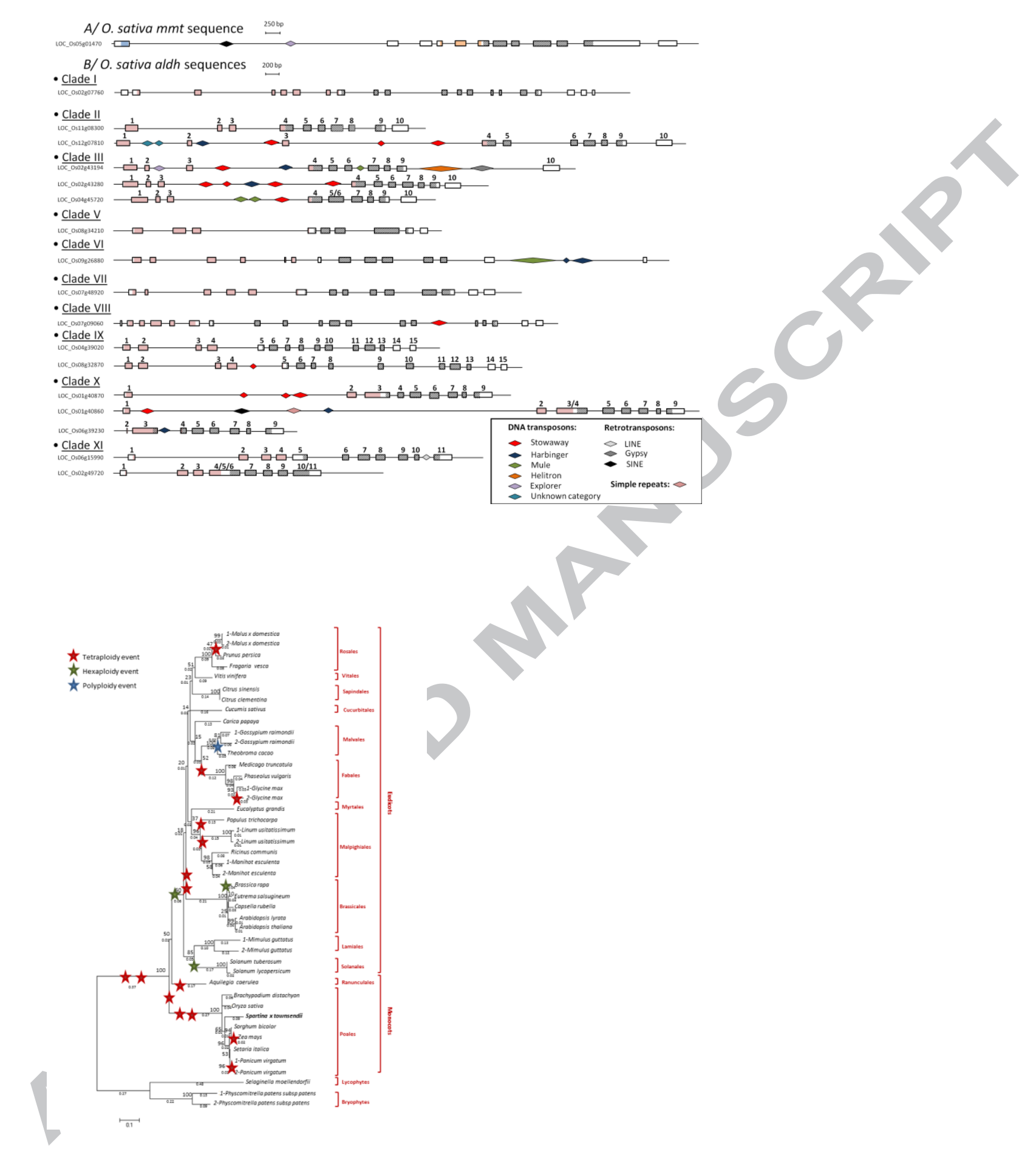



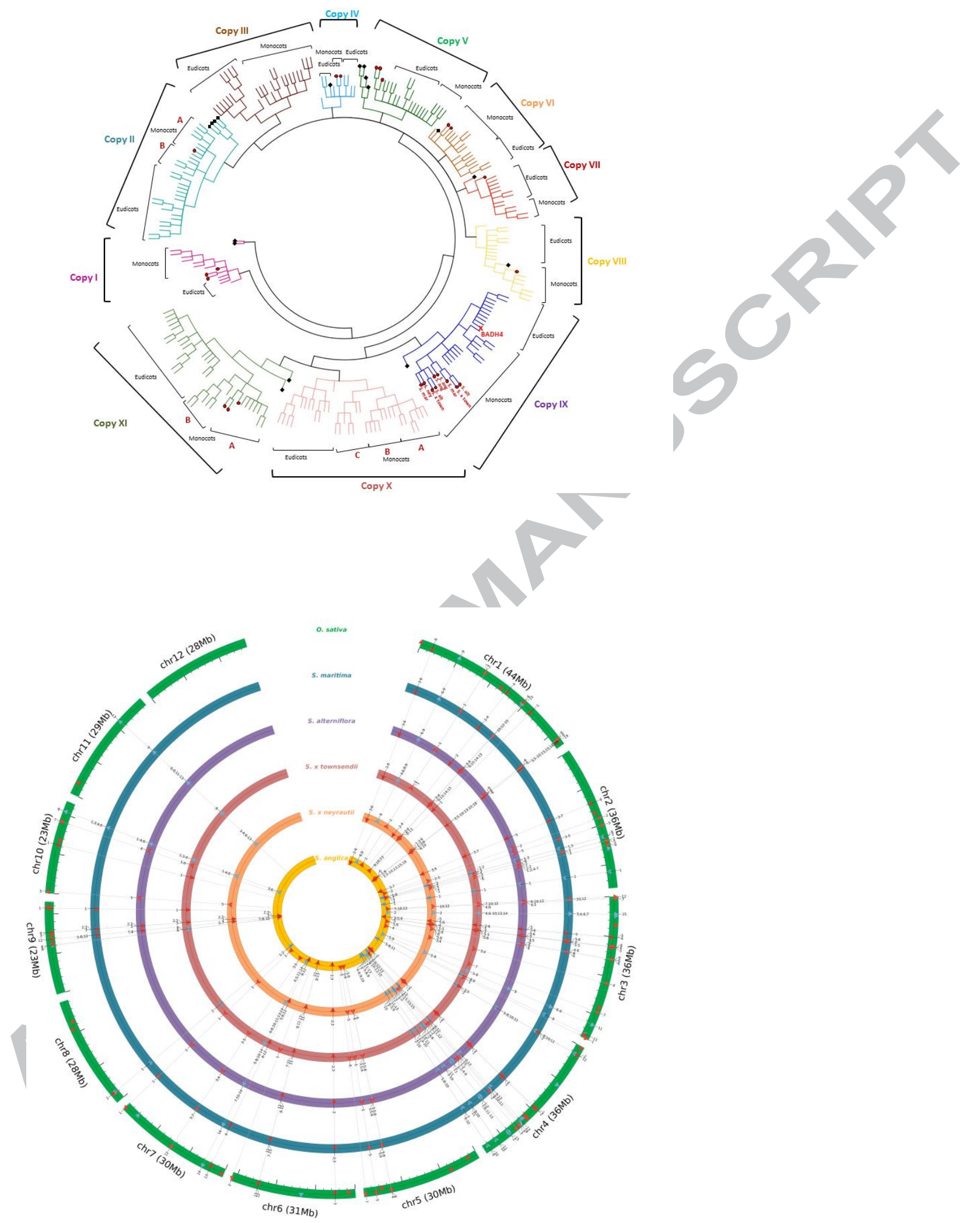


\section{Highlights}

- The ability to produce DMSP was explored in Spartina in the light of the species phylogeny and ploidy

- DMSP synthesis evolved once in a hexaploid lineage and was transmitted to derived species

- Candidate genes involved in the DMSP biosynthetic pathway were identified in Spartina

- Comparative analyses of the genes involved in the DMSP biosynthesis pathway

- Hypotheses regarding DMSP synthesis and role in plants are discussed

Graphical abstract

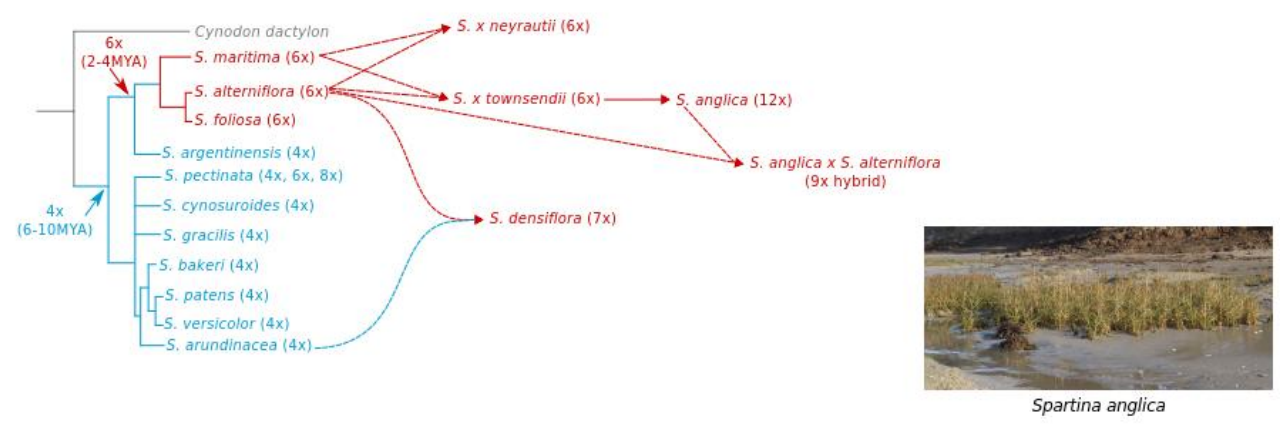

